\section{MBE for orthodontic nurse}

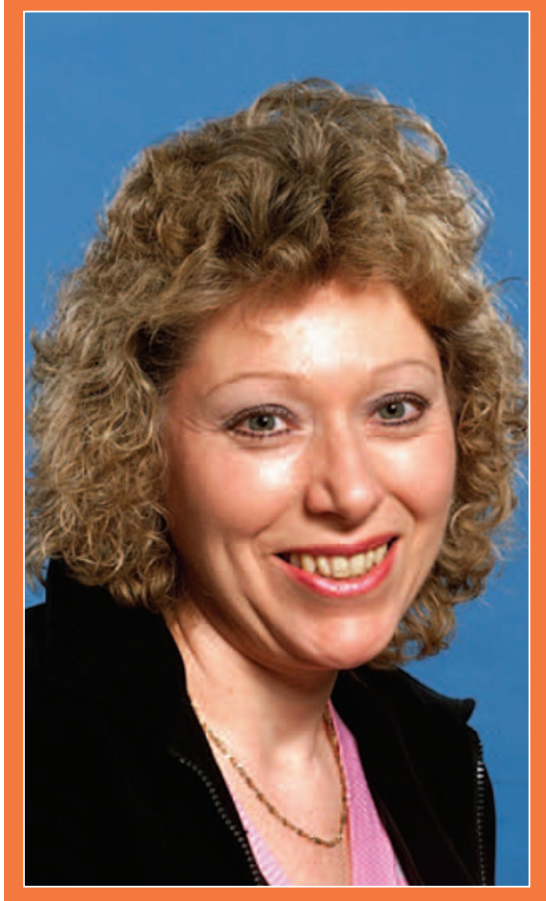

An MBE has been awarded to Alex Moss, Head Nurse in the Department of Orthodontics at the Eastman Dental Hospital, for her part in developing orthodontic nursing as a recognised dental care professional (DCP) role with its own qualification.

Currently the British Orthodontic Society representative on the General Dental Council's (GDC) Education Committee for DCPs, Alex has sat on a number of strategic working parties for the GDC. She has also helped develop a curriculum for orthodontic therapists.

Alex has met and provided evidence for the Nuffield Inquiry Committee, the English and Scottish Chief Dental Officers, the Royal College of Surgeons of Edinburgh, Healthcare (UK) and the Knowledge \& Skills Framework Group of the NHS Staff Council.

She has been Head Dental Nurse in the Department of Orthodontics at the Eastman, part of University College London Hospitals NHS Foundation Trust, for more than 30 years.

\title{
CDTs make history
}

The Faculty of General Dental Practice (UK) and Kent, Surrey and Sussex (KSS) Deanery are celebrating a milestone in UK dentistry, as the first graduates of the Diploma in Clinical Dental Technology received their award at a ceremony earlier this summer.

The diploma programme was established to provide clinical dental technicians (CDTs) with a route to registration with the General Dental Council (GDC) after it introduced the role to the dental team in 2006. Having previously completed the Diploma in Clinical Dental Technology from the George Brown College in Toronto, diplomates undertook training provided by the University of Kent in association with the KSS Deanery, followed by assessment via written examination and portfolio of evidence, leading to the award of the diploma by the FGDP (UK).

Speaking at the ceremony, which was held at The Royal College of Surgeons of England, FGDP (UK) Dean Richard Hayward congratulated those who had successfully completed the programme, 30 of whom now appear on the GDC register.

Lee Butler, a CDT based in Hampshire who has recently joined the GDC register, said after the ceremony, 'Receiving this diploma has been the single most important point so far in my professional development.'

The role of the CDT includes assessing patients for, manufacturing and fitting full dentures. Under new legislation, CDTs will be able to see totally edentulous patients without prior review from a dentist, and make partial dentures for patients on receipt of a referral and signed treatment plan from a dentist.

The FGDP (UK) is beginning consultation on the development of a full UK-based route to registration as a CDT. Dental technicians who are eligible for GDC registration and who would like to register an interest in such a programme should contact Sally Hunter, FGDP (UK) DCP Officer, on 02078696766 or shunter@rcseng.ac.uk, to be added to a mailing list for future information.

\section{First graduating dental hygienists and therapists}

The first students to complete Scotland's only degree programme for dental hygienists and therapists have recently graduated from the University of Dundee. The BSc in Oral Health Sciences has been designed to help meet the demand for dental care provision in the UK, where there is a current shortage of staff in many sectors.

Course director Dr Ann Shearer, of the University of Dundee Dental School, said

\section{New leader for BADT}

Leigh Ann Randell was installed as new President of the British Association of Dental Therapists (BADT) in June this year. Leigh Ann is a dually-qualified dental hygienist/therapist and has been involved in BADT council for several years, most recently as Chairman. Outgoing President Hazel Fraser has been a great ambassador for the Association over the the course would go some way to meeting the demand for new talent in the dental healthcare system. She said, 'It is hoped that this course, and similar courses elsewhere in the UK, will help address the demand for dental treatment. The course is the only degree programme in Scotland for dental hygienists and therapists, and our graduates will bring much needed skills and talent into the system.'

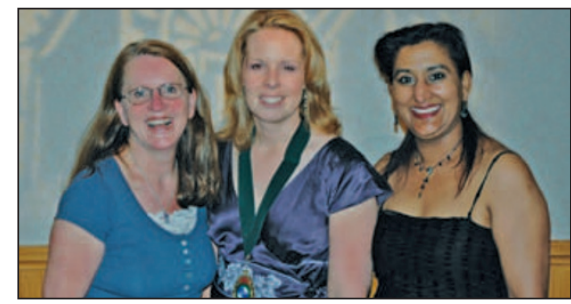

Hazel Fraser, outgoing President, Leigh Ann Randell, President and Baldeesh Chana, Chairman

past four years, and Leigh Ann hopes to follow in her footsteps and represent BADT across the dental profession. 